\section{RMD Open}

Rheumatic \&

Musculoskeletal Diseases

\title{
Considerations for improving quality of care of patients with rheumatoid arthritis and associated comorbidities
}

Tore K Kvien (D), ${ }^{1}$ Alejandro Balsa, ${ }^{2}$ Neil Betteridge, ${ }^{3}$ Maya H Buch (D, $, 4,5$ Patrick Durez (D), ${ }^{6}$ Ennio Giulio Favalli (D), ${ }^{7}$ Guillaume Favier (D), ${ }^{8}$ Cem Gabay, ${ }^{9}$ Rinie Geenen, ${ }^{10}$ Ioanna Gouni-Berthold, ${ }^{11}$ Frank van den Hoogen, ${ }^{12,13}$ Alison Kent, ${ }^{14}$ Lars Klareskog (D, ${ }^{15}$ Mikkel Ostergaard, ${ }^{16}$ Karel Pavelka, ${ }^{17}$ Joaquim Polido Pereira, ${ }^{18}$ Anne Grete Semb, ${ }^{1}$ Magnus Sköld, ${ }^{19,20}$ Maxime Dougados ${ }^{21}$

To cite: Kvien TK, Balsa A, Betteridge N, et al. Considerations for improving quality of care of patients with rheumatoid arthritis and associated comorbidities. RMD Open 2020;6:e001211. doi:10.1136/rmdopen-2020001211

Received 24 February 2020 Revised 29 May 2020 Accepted 8 June 2020
Check for updates

(C) Author(s) (or their employer(s)) 2020. Re-use permitted under CC BY-NC. No commercial re-use. See rights and permissions. Published by BMJ.

For numbered affiliations see end of article.

Correspondence to

Tore K Kvien; t.k.kvien@medi sin.uio.no

\section{ABSTRACT}

Objective Rheumatoid arthritis (RA) is a chronic autoimmune inflammatory disorder with a global prevalence of approximately $0.5-1 \%$. Patients with RA are at an increased risk of developing comorbidities (eg, cardiovascular disease, pulmonary disease, diabetes and depression). Despite this, there are limited recommendations for the management and implementation of associated comorbidities. This study aimed to identify good practice interventions in the care of RA and associated comorbidities.

Methods A combination of primary research (180+ interviews with specialists across 12 European rheumatology centres) and secondary research (literature review of existing publications and guidelines/recommendations) were used to identify challenges in management and corresponding good practice interventions. Findings were prioritised and reviewed by a group of 18 rheumatology experts including rheumatologists, comorbidity experts, a patient representative and a highly specialised nurse. Results Challenges throughout the patient pathway (including delays in diagnosis and referral, shortage of rheumatologists, limited awareness of primary care professionals) and 18 good practice interventions were identified in the study. The expert group segmented and prioritised interventions according to three distinct stages of the disease: (1) suspected RA, (2) recent diagnosis of RA and (3) established RA. Examples of good practice interventions included enabling self-management (self-monitoring and disease management support, for example, lifestyle adaptations); early arthritis clinic; rapid access to care (online referral, triage, ultrasound-guided diagnosis); dedicated comorbidity specialists; enhanced communication with primary care (hotline, education sessions); and integrating patient registries into daily clinical practice.

Conclusion Learning from implementation of good practice interventions in centres across Europe provides an opportunity to more widely improved care for patients with RA and associated comorbidities.

\section{Key messages}

What is already known about this subject

- RA has a global prevalence of about $0.5-1 \%$. The global burden of RA has risen, despite no significant change in prevalence.

- Despite publication of international guidelines and recommendations on RA management, there are limited international recommendations on the management of the several RA-associated comorbidities.

- There are many challenges in the delivery for RA care and associated comorbidities which exist at the level of the healthcare system, healthcare providers and patient, across the patient pathways.

What does this study add

- This initiative highlights good practice interventions which are in place at selected centres across Europe and addresses some of the challenges as well as opportunities in delivery of care.

- An expert multi-disciplinary panel consisting of rheumatologists, specialists in associated comorbidities, a patient representative and a highly specialist nurse prioritised, by consensus, the good practice interventions at three different disease stages; suspected RA, recent diagnosis of RA and established RA.

- The study findings inform European considerations on good practice management of RA and associated comorbidities.

How might this impact on clinical practice

- The interventions highlighted in this report could be potentially implemented by and adapted to varying healthcare settings to improve the quality of care of patients with RA and their associated comorbidities.

\section{INTRODUCTION}

Rheumatoid arthritis (RA) is one of the most common autoimmune inflammatory diseases worldwide, ${ }^{1}$ affecting between $0.5 \%$ and $1 \%$ of 
the global population. ${ }^{2}$ Although life expectancy of patients with RA has increased over the last decades, ${ }^{3}$ they are still at increased risk of developing comorbid conditions. ${ }^{4}$

Comorbidities discussed in this paper refer to conditions that may either be directly or indirectly caused by RA, RA treatment or by RA outcomes, such as decreased mobility and functional impairment. Multi-morbidities related to increasing age and lifestyles of patients with RA are also of note and included in this paper's definition of comorbidities. ${ }^{5}$

When compared to the general population, patients with RA have the following adjusted lifetime HRs: 1.41 for the development of cardiovascular disease (40-70\% increased risk), ${ }^{6} 896$ for interstitial lung disease (ILD) $(7 \% \text { increased risk })^{7}$ and 15 for diabetes. ${ }^{8}$ Estimates of the prevalence of depressive disorder in patients with RA range between $13 \%$ and $20 \%{ }^{910}$ which is $2-3$ times higher than for the general population while the disabilityadjusted life years of patients with RA has increased from 3.3 million in 1990 to 4.8 million in $2010 .{ }^{11}$

Guidelines and recommendations, such as the 2016 EULAR points to consider for reporting, screening for and preventing selected comorbidities, ${ }^{12}$ primarily address screening and prevention of comorbidities. However, there is a clear need for recommendations on the management of RA-associated comorbidities. ${ }^{13}$

The objectives of this study were to (1) understand the current challenges in the management of patients living with RA and associated comorbidities, (2) identify and collate approaches undertaken by rheumatology teams to address these challenges and (3) discuss potential strategies to replicate and implement these interventions across healthcare systems and care settings to improve patient outcomes.

\section{MATERIALS AND METHODS}

The study followed a three-step approach:

1. A literature review using an integrative approach to identify reported and evidence-based challenges and good practice examples in the management of RA and its associated comorbidities. The review included

- Academic literature search. A database search for articles in PubMed using a combination of prioritised search terms was conducted. The search terms included rheumatoid arthritis, comorbidities, cardiovascular risk, diabetes, depression, interstitial lung disease, management, early identification, diagnosis, challenges in care, patient outcomes, guidelines, recommendation, quality of care, screening, diagnosis, delay referral, treat to target, disease burden, multidisciplinary approach to care, self-management, personalised care, etc. Additional articles were retrieved through the citation-tracking of original publications and were based on the recommendation from the expert panel.
- Grey literature search. The publicly available grey literature was investigated by applying the same prioritised search terms in search engines. Non-Englishlanguage references were excluded unless there was sufficient explanatory text in English. The time allotted for the grey literature search was 1 hour or until saturation was reached, whichever came first. Saturation was defined as not identifying new literature to include in analysis for $40 \mathrm{~min}$ or five consecutive search pages, whichever came first.

2. Visits to 12 RA centres across Europe, representing a multinational approach to RA management with each centre being located in a different European country. The centres were selected based on a set of criteria which included

- Geography: the centres, each located in a different European country, were selected to represent a multinational approach to RA management.

- Focus: the centre's experience with RA was considered; both specialised and more generalist centres were selected to ensure the results of the study would be applicable to the wider clinical community.

- Centre type: the centres' models and involvement in the wider healthcare ecosystem (eg, private vs public funding, size, partnerships within the community, etc) were assessed.

Participating centres included Diakonhjemmet Hospital (Oslo, Norway), Cochin Hospital (Paris, France), Institute of Rheumatology (Prague, Czech Republic), Hospital Santa Maria (Lisbon, Portugal), University Hospital La Paz (Madrid, Spain), Chapel Allerton Hospital and University of Leeds (Leeds, UK), University Clinic Saint-Luc (Brussels, Belgium), Geneva University Hospital (Geneva, Switzerland), Sint Maartenskliniek (Nijmegen, Netherlands), Karolinska University Hospital and the Centre for Rheumatology (Stockholm, Sweden), Rigshospitalet (Copenhagen, Denmark) and ASST Gaetano Pini-CTO Institute (Milan, Italy).

Approximately 180 qualitative semi-structured interviews were conducted to gain a robust understanding of the management of RA and associated comorbidities through the visits. An interview guide was created to facilitate the structured collection of quantitative and qualitative insights. The questions were designed to capture the RA service set-up and patient pathway design within each centre and assessing the key challenges, which were categorised as 'gaps in care' and 'drivers' (ie, reasons for gaps in care).

All the interviews were conducted on an individual basis over a duration of approximately 1 hour. Before the start of the interview, all participants were given an overview of the project objectives.

The individuals interviewed included a wide range of healthcare professionals (HCPs) such as rheumatologists, nurses, physiotherapists, occupational therapists and RAassociated comorbidity specialists, pharmacists, practice management. 
Interview responses were systematically analysed for insights and patterns. Thematic analysis was undertaken to identify all challenges and interventions, which were subsequently reviewed by the expert panel.

3. The findings from the above secondary and primary research were tested with an expert panel. This panel of European experts was set up to ensure relevance in a range of healthcare systems. It consisted of 18 members including 16 clinicians of which there were 12 rheumatologists (one from each centre visited), 1 cardiologist, 1 pulmonologist, 1 diabetologist and 1 psychologist (ie, one representative for the four preselected common comorbidities). The panel also included one rheumatology specialist nurse, acknowledging evidence that highlights the importance of the role of nurses in practice and one patient representative to capture the views and perspectives of patients. The expert panel was involved throughout the study and met on three occasions to guide the project objectives and discuss project findings. Ethical approval was not required for this study, since it did not include data collection from patients or other individuals.

\section{RESULTS}

Several challenges in the management of RA and associated comorbidities were identified. Gaps in the care of patients with RA included the following: delays in securing a diagnosis consisting of seeking medical advice ( $>12$ weeks ${ }^{14}$ ); referral delays (with a median of 4 visits to the general practitioner before patients are referred to a rheumatologist ${ }^{15}$ ) leading to an overall delay in diagnosis (in several countries, it can take up to a year from symptom onset ${ }^{16}$ ); and upon diagnosis and treatment initiation, poor patient adherence to therapy (varying between $30 \%$ and $80 \%{ }^{17}$ ) and lack of monitoring (up to $50 \%$ of patients do not have access to an regular review in a secondary care setting. ${ }^{18}$ ) Drivers of these gaps in care were evident at a healthcare system, patient and HCP level (table 1).

Challenges were also evident throughout the patient pathway for the care of RA-associated comorbidities. One pertinent challenge was the limited guidance for the care of comorbidities in patients with RA (table 2).

Table 1 Gaps in care and their associated drivers evident across the journey of patients with RA

\begin{tabular}{lll}
\hline Stage of patient journey & Gaps in care & Drivers \\
\hline Awareness and prevention & $\begin{array}{l}\text { Delays in patients seeking } \\
\text { medical advice }\end{array}$ & Low public awareness $^{14}$ \\
& Lack of patient education $^{19}$
\end{tabular}

Referral

Delayed referrals from PCPs to rheumatologist

\author{
Follow-up
}

Delay in diagnosis

Delayed treatment
initiation
Poor patient adherence to
therapy
Lack of coordinated
treatment

Lack of monitoring Suboptimal patient outcomes
Limited awareness of PCPs on signs and symptoms of $\mathrm{RA}^{20}$

Long waiting times for specialists ${ }^{21}$

Joint stiffness and inflammation are common for many other conditions

Lack of knowledge regarding the referral pathway or the importance of rapid referral ${ }^{21}$

Complex diagnostic requirements ${ }^{14}$

Limited availability of imaging facilities ${ }^{21} 22$

Shortage of rheumatologists ${ }^{22}$

Limited number of HCPs trained to interpret diagnostic results (including imaging) ${ }^{14}$

Budgetary cap and restrictive clinical recommendations regarding choice of therapy ${ }^{22}$

Disease management not aimed at optimising quality of life $\mathrm{e}^{23}$

Deviation from recommendations, or difficulty in implementing them into clinical practice ${ }^{22}$

Lack of regular review and engagement with patients' needs $^{24}$

Treatment adherence ${ }^{23}$

Competing lifestyle factors ${ }^{23}$

Capacity constraint-leading to long waiting time for examinations with imaging modalities ${ }^{22}$

Lack of regularity in follow-up care ${ }^{22}$ Access to rheumatologists ${ }^{22}$

*List not exhaustive.

HCP, healthcare professional; PCP, primary care professional; RA, rheumatoid arthritis. 
Table 2 Gaps in care and their associated drivers evident across the journey of patients with RA-associated comorbidities

\begin{tabular}{|c|c|c|}
\hline Stage of patient journey & Gaps in care & Drivers* \\
\hline Screening & $\begin{array}{l}\text { Lack of screening for } \\
\text { comorbidity risk factors }\end{array}$ & $\begin{array}{l}\text { Limited screening pathways and frameworks in place to } \\
\text { detect comorbidities among patients with } \mathrm{RA}^{25} \\
\text { Lack of comprehensive comorbidity-specific } \\
\text { recommendations } \\
\text { Limited comorbidity screening }\end{array}$ \\
\hline Referral & Delay in referral & $\begin{array}{l}\text { Lack of HCP education on referral pathways }{ }^{27} \\
\text { Logistical and ambulatory difficulty can negatively impact } \\
\text { outpatient attendance }{ }^{28}\end{array}$ \\
\hline Diagnosis & Delay in diagnosis & $\begin{array}{l}\text { Comorbidities are often underdiagnosed and more likely to } \\
\text { be diagnosed when severe } \\
\text { Symptoms of RA/RA treatment can mask comorbidity } \\
\text { signs and symptoms }{ }^{29}\end{array}$ \\
\hline $\begin{array}{l}\text { Treatment and management } \\
\text { (pharmacological and non- } \\
\text { pharmacological) }\end{array}$ & $\begin{array}{l}\text { Inadequate } \\
\text { management of } \\
\text { comorbidities }\end{array}$ & $\begin{array}{l}\text { Inadequate communication across multidisciplinary } \\
\text { team }^{25} \\
\text { Limited recording of drug-drug interactions } \\
\text { Patients with RA who have comorbidities do not always } \\
\text { receive the recommended comorbidity treatment }{ }^{25}\end{array}$ \\
\hline Follow-up & $\begin{array}{l}\text { Suboptimal patient } \\
\text { outcomes }\end{array}$ & $\begin{array}{l}\text { Issues with patient data inconsistencies in capturing and } \\
\text { sharing across different systems }{ }^{29} \\
\text { Poor follow-up appointment attendance }{ }^{27} \\
\text { Increased morbidity and mortality is seen in patients with } \\
\text { complex therapeutic needs }{ }^{27}\end{array}$ \\
\hline
\end{tabular}

*List of drivers not exhaustive.

$\mathrm{HCP}$, healthcare professional; $\mathrm{PCP}$, primary care professional; RA, rheumatoid arthritis.

Through secondary research, several guidelines and recommendations were identified for some comorbidities, but the presence of guidelines differed depending on the comorbidity (table 3 ).

The expert panel recommended to frame the findings of the study against three different stages of disease (table 4).

These disease stages were used to segment and prioritise good practice interventions. In total, 18 good practice interventions were identified, through the centre visits, which span across the whole patient pathway. Interventions were highlighted as applicable to one, multiple or all disease stages (table 5).

All 18 interventions were reviewed by the expert panel and prioritised by ranking the highest impact on patient outcomes, against each stage of the disease: suspicion of RA; recent diagnosis of RA; established disease (while recognising that for each one of them, patients have distinct needs and requirements). The top three interventions for each disease stage are shown in table 6 and are described in the following sections.

\section{Interventions: diagnosing RA and early intervention}

Rapid access to specialised care

Patients with suspected RA must be seen rapidly to facilitate the effective prevention and management of disease progression and joint damage. ${ }^{37}$ Delays in diagnosis and referral from primary care mean patients can arrive at secondary centres with irreversible damage to their joints and other organs. It is vital that these patients are triaged rapidly into care and start treatment straight away. ${ }^{38}$ Rapid access to care may include online referral systems (patient self-enrollment) and access to diagnostic services (eg, blood tests and ultrasound). Hospital Universitario La Paz has implemented an online direct communication system between the rheumatology department and primary care practitioners to allow two-way messaging system for rapid patient referrals within 24 hours. Several centres run rapid access clinics, such as the 'clinically suspect arthralgia' clinic for undifferentiated arthralgia at the Institute of Rheumatology in the Czech Republic, the pre-RA CCP clinic Leeds Hospital in the UK and the sophisticated triaging system at Hospital de Santa Maria which aims to increase accessibility for new patients and rapidly assess the presence and severity of RA. These services have reduced waiting times, improved the experience for patients and facilitated two-way communication between primary and secondary care.

\section{Early arthritis clinic}

Early treatment reduces overall disease progression and therefore prevents the accumulation of damage that causes irreversible joint deformities. Clinics are dedicated to ensuring timely clinical assessment and diagnosis of patients with suspected RA, including initial triage, to which patients can be referred by 
Table 3 Guidelines and/or recommendations present for comorbidities in RA

\begin{tabular}{|c|c|c|}
\hline Comorbidity & Authors & Guidelines/recommendations \\
\hline $\begin{array}{l}\text { Cardiovascular } \\
\text { disease }\end{array}$ & Regulatory bodies or disease associations & $\begin{array}{l}\text { 1. } 2016 \text { Update EULAR recommendations for CVD risk } \\
\text { management. } \\
\text { 2. } 2016 \text { EULAR points to consider for reporting, screening } \\
\text { for and preventing selected comorbidities. }{ }^{12} \\
\text { 3. } 2019 \text { European Society of Cardiology/European } \\
\text { Atherosclerosis Society guidelines for the management of } \\
\text { dyslipidaemias. }{ }^{31} \\
\text { 4. Spanish Society of Rheumatology (2011). Update of the } \\
\text { clinical practice guideline for the management of }_{\text {rheumatoid arthritis in Spain. }{ }^{32}} \\
\text { 5. Haute Autorite De Sante ( } 2017) \text { : Clinical practice } \\
\text { guidelines: Rheumatoid Arthritis }\end{array}$ \\
\hline $\begin{array}{l}\text { Pulmonary } \\
\text { disease }\end{array}$ & Academic literature & $\begin{array}{l}\text { 1. Diagnosis of Idiopathic Pulmonary Fibrosis. An Official } \\
\text { ATS/ERS/JRS/ALAT Clinical Practice Guideline } \\
\text { (associated rheumatological diseases are discussed from } \\
\text { a pulmonary perspective) } \\
\text { 2. } 2019 \text { Swedish Respiratory Society Guidelines for } \\
\text { Idiopathic Pulmonary Fibrosis } \\
35\end{array}$ \\
\hline Diabetes & $\begin{array}{l}\text { No existing guidelines or recommendations } \\
\text { were found at a regional or national level for } \\
\text { diabetes }\end{array}$ & \\
\hline Depression & $\begin{array}{l}\text { Existing recommendations/points to consider } \\
\text { published by regulatory bodies or disease } \\
\text { associations }\end{array}$ & $\begin{array}{l}\text { 1. } 2016 \text { EULAR points to consider for reporting, screening } \\
\text { for and preventing selected comorbidities. }{ }^{12} \\
\text { 2. NICE (2009): Depression in adults with a chronic physical } \\
\text { health problem: recognition and management }{ }^{36}\end{array}$ \\
\hline
\end{tabular}

ALAT, L;atin American Thoracic Association; ATS, American Thoracic Society; CVD, cardiovascular disease; ERS, European Respiratory Society; JRS, Japanese Respiratory Society; NICE, National Institute for Health and Care Excellence; RA, rheumatoid arthritis.

primary care physicians (PCPs) and other specialists. The Institute of Rheumatology, Hospital de Santa Maria, Cliniques Universitaires Saint-Luc, Sint Maartenskliniek, Diakonhjemmet Hospital, Leeds Teaching Hospitals, Karolinska University Hospital, Hospital Universitario La Paz, ASST Gaetano PiniCTO Institute and Rigshospitalet have all implemented early arthritis clinics leading to more patients being diagnosed quickly and starting early diseasemodifying therapy combined with a treat-to-target strategy; with follow-up maintained in the early arthritis clinic until target is reached and/or directed to escalated treatment pathways and service as indicated.

\section{Enhanced communication with primary care}

Often patients are not transitioned between different levels of the healthcare system in a timely manner ${ }^{21}$ which can be due to several factors including lack of awareness of referral pathways and systems, suboptimal communication between specialists and PCPs, and sharing of up-to-date patient information. ${ }^{22}$ Enhanced communication strategies identified include a hotline for PCPs to access specialist advice within 48 hours,

\section{Table 4 Disease stages}

\begin{tabular}{|c|c|}
\hline Disease stage & Description \\
\hline Suspicion of RA & $\begin{array}{l}\text { Patients who have not yet been given a diagnosis but may have interacted with primary care or } \\
\text { had a first contact with a rheumatologist, and who may have suspected RA (inflammatory } \\
\text { manifestations not diagnosed) }\end{array}$ \\
\hline Recent diagnosis of RA & $\begin{array}{l}\text { Patients have been given a diagnosis of RA and usually have been started on treatment with } \\
\text { regular follow-up }\end{array}$ \\
\hline $\begin{array}{l}\text { Established disease/ } \\
\text { structural damage }\end{array}$ & $\begin{array}{l}\text { Patients have had a diagnosis of RA for several years or may have presented late (most likely } \\
\text { from less developed healthcare economies). At this stage, treatments may have become } \\
\text { progressively less effective at reducing inflammation and preventing further joint damage }\end{array}$ \\
\hline
\end{tabular}

$\mathrm{RA}$, rheumatoid arthritis. 
Table 5 Good practice interventions relevant to the three disease stages of patients with RA

\begin{tabular}{l} 
Intervention \\
\hline Rapid access to care \\
Enhanced \\
communication across \\
wider care team
\end{tabular}

Definition

Recently

Established

Fast-track access to care for patients with RA done via online referral form reviewed every 24 hours, hotline leading to appointments within 48 hours for diagnostic services including blood tests and joint imaging

Availability of reliable communication channels (eg, emails, online forms) enabling easy dialogue between specialists and PCPs; and providing and coordinating education programmes to ensure the wider care team are kept up-to-date with developments in best practice care

Early arthritic clinic
Comprehensive
comorbidity assessment

Clinic dedicated to ensuring timely clinical assessment and diagnosis of patients with suspected RA

Comorbidity assessment in patient baseline

$\begin{array}{lll}\begin{array}{l}\text { Suspected } \\ \text { RA }\end{array} & \begin{array}{l}\text { Recently } \\ \text { diagnosed } \\ \text { with RA }\end{array} & \begin{array}{l}\text { Established } \\ \text { RA/structural } \\ \text { damage }\end{array} \\ \mathrm{X} & \mathrm{X} & \mathrm{X} \\ & & \\ \mathrm{X} & \mathrm{X} & \mathrm{X}\end{array}$

Tailored education to
patients and family
members
Role of the care
coordinator
Dedicated comorbidity
specialist HCP
Enabling self-
management

patients

Programmes to increase understanding of diagnosis, treatment plans, and how to live with the disease that is sensitive to individual patient needs

Care coordinator role to help to manage the burden of navigating contacts across multiple HCPs

Specific role or clinic to support the management of comorbidities in the context of RA

Provision of tools and resources to patients to monitor and manage their RA and reduce dependence on healthcare services

$\begin{array}{llll}\text { Enhanced therapy } & \begin{array}{l}\text { Additional care centred around non-physician-led } \\ \text { management including care led by therapists to } \\ \text { promote rehabilitation and enablement }\end{array} & \text { X } \\ \text { Day clinic services } & \begin{array}{l}\text { The coordination of services enabling provision of } \\ \text { stacked outpatient appointments across specialities } \\ \text { and disciplines over 1 day or session }\end{array} & \text { X } & \text { X }\end{array}$

\begin{tabular}{|c|c|c|c|c|}
\hline $\begin{array}{l}\text { Virtual engagement with } \\
\text { patients }\end{array}$ & $\begin{array}{l}\text { Digital enablement of autonomy, self-management } \\
\text { and empowerment by providing a channel of direct } \\
\text { communication with attending physicians in addition } \\
\text { to online access to education around the disease, } \\
\text { networks and peer support }\end{array}$ & $x$ & $x$ & $x$ \\
\hline $\begin{array}{l}\text { Integrating patient } \\
\text { registries into daily clinical } \\
\text { practice }\end{array}$ & $\begin{array}{l}\text { Employment of evidence-based practice, informed } \\
\text { by clinical research and supported by systematic } \\
\text { capture and monitoring of data, in order to improve } \\
\text { the quality of clinical care delivery and promote } \\
\text { evolution of care models }\end{array}$ & $X$ & $X$ & $x$ \\
\hline $\begin{array}{l}\text { Patient-centred care } \\
\text { journey }\end{array}$ & $\begin{array}{l}\text { Curation of care processes and physical environment } \\
\text { that enables the patient to feel empowered and } \\
\text { supported during their journey through care }\end{array}$ & $x$ & $X$ & $x$ \\
\hline $\begin{array}{l}\text { Effectively using the skill } \\
\text { mix of the } \\
\text { multidisciplinary care } \\
\text { team }\end{array}$ & $\begin{array}{l}\text { Enablement of non-physician HCPs to taking on } \\
\text { greater responsibility in the assessment and } \\
\text { management of patients }\end{array}$ & $x$ & $X$ & $X$ \\
\hline $\begin{array}{l}\text { Integrative and shared } \\
\text { care solutions }\end{array}$ & $\begin{array}{l}\text { Ensuring regular communication between all } \\
\text { attending physicians and other HCPs as part of } \\
\text { a holistic and integrated approach to care }\end{array}$ & $x$ & $X$ & $X$ \\
\hline
\end{tabular}


Table 5 Continued

\begin{tabular}{|c|c|c|c|c|}
\hline Intervention & Definition & $\begin{array}{l}\text { Suspected } \\
\text { RA }\end{array}$ & $\begin{array}{l}\text { Recently } \\
\text { diagnosed } \\
\text { with RA }\end{array}$ & $\begin{array}{l}\text { Established } \\
\text { RA/structural } \\
\text { damage }\end{array}$ \\
\hline Collaborating with PAGs & $\begin{array}{l}\text { Increasing communication with local and regional } \\
\text { patient advocacy groups through working group } \\
\text { sessions, conference attendance, newsletters and } \\
\text { patient liaisons }\end{array}$ & $x$ & $\mathrm{X}$ & $x$ \\
\hline Developing care networks & $\begin{array}{l}\text { Developing networks with community-based RA } \\
\text { services to maintain high-quality 'joined-up' care past } \\
\text { the point of discharge }\end{array}$ & $x$ & $x$ & $x$ \\
\hline $\begin{array}{l}\text { Quality management } \\
\text { programmes }\end{array}$ & $\begin{array}{l}\text { A coordinated approach and a robust system for } \\
\text { measuring, tracking and improving the quality of care }\end{array}$ & $X$ & $x$ & $x$ \\
\hline
\end{tabular}

HCPs, healthcare professionals; PAGs, patient advocacy groups; PCPs, primary care professionals; RA, rheumatoid arthritis.

linked information systems leading to collaboration between primary and secondary care, educational and training sessions. Hôpital Cochin implemented the 'Hospital and City Rheumatology Network' and Diakonhjemmet Hospital have a dedicated primary care coordinator. ASST Gaetano Pini-CTO Institute delivers education and training for PCPs in Italy regarding RA, developing a network with primary care. Enhanced communication facilitates improved integration of services and patients accessing specialist treatment in a timely manner.

\section{Interventions: management of comorbidities}

Comprehensive comorbidity assessment

Certain patients with RA are at increased risk of morbidity and mortality due to existence of comorbidities such as cardiovascular disease, ILD, diabetes and depression. ${ }^{25} 262939$ Systems for cross-specialty care and follow-up can be fragmented. ${ }^{25}$ Centres may implement regular (typically 6-monthly) full

\begin{tabular}{ll}
\hline Table 6 Prioritised interventions per disease stage \\
\hline Disease stage & Prioritised interventions* \\
\hline Suspicion of RA & $\begin{array}{l}\text { 1. Rapid access to care. } \\
\text { 2. Enhanced communication with } \\
\text { primary care. }\end{array}$ \\
& $\begin{array}{l}\text { 3. Early arthritis clinic. } \\
\text { Recent diagnosis of RA }\end{array}$ \\
$\begin{array}{ll}\text { 1. Enabling self-management. } \\
\text { 2. Early arthritis clinic. }\end{array}$ \\
$\begin{array}{ll}\text { 3. Comprehensive comorbidity } \\
\text { assessment. }\end{array}$ \\
structural damage & $\begin{array}{l}\text { 1. Dedicated comorbidity } \\
\text { specialist. }\end{array}$ \\
& $\begin{array}{l}\text { 2. Integrating patient registries into } \\
\text { daily clinical practice. }\end{array}$ \\
& 3. Enabling self-management.
\end{tabular}

${ }^{*}$ The top three priority interventions are listed.

$\mathrm{RA}$, rheumatoid arthritis. comorbidity assessment as a standalone service or in conjunction with RA appointments. Hôpital Cochin has a Comorbidities Education in Rheumatoid Arthritis (COMEDRA) service which is a doctor-led programme on RA comorbidity management and supported by a programme coordinator, and Hospital Universitario La Paz has a systematic inflammatory osteoporosis screening. Comorbidity assessments may lead to reduced patient mortality due to comorbidity complications in patients with RA (eg, cardiovascular disease and ILD).

\section{Dedicated comorbidity specialist}

Comorbid diseases may not always be given appropriate focus and attention because rheumatologists are not specialists in these areas. ${ }^{24}$ To overcome this, centres may deploy an in-house comorbidity specialist for example, a cardiologist dedicated to the cardiovascular manifestations of rheumatic disorders. Diakonhjemmet Hospital has a preventive cardio-rheuma clinic run by a cardiologist employed in the Department of Rheumatology, and Hospital de Santa Maria has a dedicated psychologist for patients with RA. The input of comorbidity specialists may raise awareness regarding comorbidities among rheumatology HCPs. At the Karolinska University Hospital, for instance, pulmonary complications can be presented during discussion rounds with the participation of pulmonologists, rheumatologists and radiologists.

\section{Combined clinics}

To effectively and more efficiently manage comorbidities associated with RA, with minimum burden on patient hospital visits, centres may implement combined clinics with both rheumatologists and the respective comorbidity specialists. Hospital de Santa Maria, ASST Gaetano Pini-CTO Institute and Hospital Universitario La Paz have combined clinics with rheumatologists and pulmonologists to manage patients with RA with or at risk of ILD. Hospital de Santa Maria has a joint rheumaobstetrics clinic to manage the potential problems that 
can arise during pregnancy in rheumatological patients. Leeds Teaching Hospitals has several joint comorbidity services with dermatology, gastroenterology, immunology, neurology, respiratory, renal and obstetrics. These combined or stand-alone clinics may cover the wider aspects of RA management, including lifestyle factors. For example, Rigshospitalet in Copenhagen offers a sleep clinic and smoking cessation clinic for patients with RA helping patients to live healthier lives. Joint clinics may lead to a greater focus on comorbidities and involvement of specialist comorbidity expertise leading to more effective decisions and better patient outcomes.

\section{Interventions: encouraging patient self-management and empowering health professionals \\ Effectively using the skill mix of the multidisciplinary care team}

The findings of this study indicated an increasing number of patients with RA requiring comprehensive care and management. Rheumatologists may not have enough time, capacity or specific skills to address these important problems outside diagnosis, inflammatory assessment and pharmacological treatment. Other health professionals (eg, nurses, physio- and occupational therapists, care coordinators and administrative staff) often have the competencies that are well suited for some of the tasks required to ensure best practice. By facilitating a more active role of these HCPs in the management of patients, they are able to bring a different dimension which adds to a holistic and patient-centred approach to care. For example, at Sint Maartenskliniek, the pharmacist is a key member of the care team, delivering medication support for patients. At Diakonhjemmet Hospital, Cliniques Universitaires Saint-Luc, Rigshospitalet and Leeds Teaching Hospitals, the enhanced role of the nurse helps support rheumatologists in care delivery (eg, in Leeds the nurse-delivered services at the centre include outpatient clinics and a day care unit where rheumatology nurses manage the delivery of biologics to patients). Such activities can be done in various ways between countries and health systems as shown in online supplementary table S1.

\section{Enabling self-management}

Patients may not always have long enough consultation sessions with rheumatologists and rheumatology nurses and other HCPs to fully educate themselves about the impact of the disease and how to manage it. $^{22}$ As part of the COMEDRA initiative at Hôpital Cochin, patients are taught to self-assess and selfmonitor their disease activity and more importantly to feel comfortable to undertake this. At Diakonhjemmet Hospital a 'learning and coping' centre is run by a multidisciplinary team led by an experienced nurse. Cliniques Universitaires Saint-Luc enables selfmanagement through personalising care delivered to patients. All these interventions have been put in place not only to improve adherence to treatment but also to help patients manage their lives and not just their disease activity; it is about empowerment and feeling in control.

\section{Interventions: care delivery process optimisation} Integrating patient registries into daily clinical practice

Several registries have been implemented at different centres to collect longitudinal real-life data, for example, at the Institute of Rheumatology; Swiss Clinical Quality Management in Rheumatic Diseases at the Hôpitaux Universitaires de Genève; Swedish Rheumatology Quality Registry at the Karolinska University Hospital and the Centre for Rheumatology in Stockholm; Danish Database for Biological Therapies at Rigshospitalet; and the Norwegian Disease-Modifying Antirheumatic Drug study at Diakonhjemmet Hospital. Hospital de Santa Maria uses the Portuguese Reuma.pt registry to support research and clinical practice and Leeds Teaching Hospitals has a focus on research to support clinical practice. Registries may inform reallife results of clinical management from different participating centres and thereby also provide information which may stimulate the different centres to improve their quality of care. Further, linkages between registries may help the understanding of the relationships between RA and comorbidities. Karolinska University Hospital has had a strong focus on this type of research. ${ }^{40} 41$

\section{Patient-centred care journey}

Patients need to be satisfied and confident with their care to be fully engaged with their care. ${ }^{42}{ }^{43}$ Patient-centred care can be defined as when patients are empowered throughout the duration of their journey whether it relates to the physical environment or the experience of the services received. At the Sint Maartenskliniek, patientcentred design reduces time spent travelling between each care station, and provides more time with the HCPs; all of which improves the overall patient experience. This intervention enables HCPs to improve patient engagement and helps empower and support patients throughout their care journey.

\section{Key considerations in selected comorbidity care for patients} with RA

The visits to study centres (primary research) and the input from the expert panel provided several key considerations for the care of comorbidities (cardiology, pulmonology, diabetes and depression) in patients with RA.

Cardiovascular disease (CVD): Key elements to consider for improvement of the quality of care of CVD in patients with RA are listed as follows:

- Communication about CVD risk factors between medical professionals as well as screening of CVD risk factors. It was noted that CVD risk prediction in patients with RA using risk calculators developed for the general population is generally inaccurate in the prediction of future CVD. ${ }^{44}$ Modifying the predicted 
risk by a 1.5 multiplier as per recommendation ${ }^{2} 46$ may also not necessarily reclassify patients to their appropriate risk class. ${ }^{28} 47$ However, adding information on carotid plaque/atherosclerosis may reclassify patients to a more appropriate risk class in up to $30-60 \%$ of cases. ${ }^{47}$

- Organisation and responsibility of CVD risk management through cardiologists working alongside or within rheumatology departments, for example, preventive cardio-rheumatology clinics. It was noted that lipid-lowering, antihypertensive therapies and nonpharmacological recommendation (eg, focusing on lifestyle factors) can be implemented safely and effectively with recommended goal achievement over approximately three consultations in $80-90 \%$ of the patients. ${ }^{48}$ Systemic inflammation or lipid levels at baseline or antirheumatic medication do not have an impact on statin dose needed to obtain low-density lipoprotein goals. ${ }^{49}$

- Availability of data regarding CVD risk management.

Pulmonary disease: Interventions and results from the study highlight the importance of early screening and detection. This can include chest X-ray, CT and functional assessment with spirometry and six-minute walking test (6MWT). Regular follow-up in outpatient clinics are also important. Management of adverse respiratory events, side effects from medications and smoking cessation advice should be included. The expert panel emphasised the importance of the fieldwork findings from the visits of study centres and especially the collaboration between rheumatologists and pulmonologists. ILD should be diagnosed in multidisciplinary discussions where the presence of rheumatologists is encouraged. These conferences can also enable pulmonologists to consider the possibility of an underlying systemic disease including RA in patients with ILD.

Diabetes: Study results highlight the importance of screening for and detecting diabetes, coordination of care between RA and diabetologists and regular follow-ups. The expert panel advised that the effective treatment of RA with targeted therapies can improve long-term glycaemic control in patients with diabetes and RA. ${ }^{50}$

Depression: The results of the study highlight the importance of screening and detection, periodic follow-up, guided self-help and targeted depression history. These can be achieved through dedicated psychological and psychiatric services as well as focusing on impacts of depression for example, sleep disturbance and socioeconomic consequences. The expert panel recommended a strong focus on prevention through paying attention to individual factors (eg, sleep, physical activity, interest in undertaking any activities), encouraging a healthy lifestyle and treatment of depression (moderate-severe) if guided selfhelp and exercise fail (eg, treatment with cognitivebehavioural treatment or psychotherapy). The expert panel noted that the ideal model to achieve the aforementioned activities would be the integration of psychology resources as part of the wider multidisciplinary team although the experts also recognised local constrains.

\section{DISCUSSION}

Challenges in the care of RA and associated comorbidities are well documented, and the results of the interviews confirmed the findings from the literature review. However, the study highlighted the different types of challenges experienced by the centres. In order to improve patient care, it is recommended that centres identify and prioritise interventions most suited to their population, patient pathways and current challenges in delivery of care. The need for comprehensive and consensusapproved guidelines and recommendations to improve the care of patients with RA and the several associated comorbidities was clear in the findings. The experts acknowledged that this requires further exploration and expert input with more robust methodology in order to develop guidelines and recommendations.

It was recognised that there were limitations to the study methodology and several actions were taken to mitigate these. One drawback was the lack of patient interviews at each individual centre which limited the patient perspective on challenges in the patient pathways and intervention benefits (eg, benefits of selfmanagement). The role of the very experienced patient representative on the expert committee (NB) helped to overcome this by providing a collective patient perspective, on behalf of patients. Second, the inclusion of one centre per country limited the findings with respect to the representativeness of the wider healthcare system in which they reside. This was taken into consideration when conducting research which did not solely focus on centres themselves but rather their entire ecosystems; including the various institutions they collaborate with, whether formally or informally. However, the goal of this study was rather to find centres that had developed good quality of care practices which could serve as models if implemented in other centres.

Third, centre selection was biased towards larger teaching centres. This was mitigated by gathering and documenting interviewees' perspectives on how to replicate interventions in smaller and less resourcerich centres, although it was accepted that this was incomplete.

The project group decided to focus on four main comorbidities; CVD, ILD, diabetes and depression. The literature review and also centre visits highlighted other comorbidities of importance. For example, it has been shown that osteoporosis is twice as common in patients with RA compared with controls of the same age $\mathrm{e}^{5152}$ and that fractures are also more common. ${ }^{46} 53$ Services to support primary and secondary prevention are of value in improving patient morbidity.

Infections are other important comorbidities which can partly be related to the disease, partly to treatment. Several studies have described treatment-related 
occurrence of infections. Importantly, EULAR has recently published updated recommendations on vaccinations, ${ }^{54}$ and editorials have addressed the important aspects of hepatitis and tuberculosis in this population. ${ }^{55}$

Guidelines and/or recommendations on periodontitis, malignancy and gastrointestinal disorders were not assessed, but it was noted that these conditions lead to poor outcomes for patients with RA. ${ }^{56-58}$

We believe that the most important message from this paper is the description of examples of good clinical practices and care models. One of the main findings was the success of early arthritis clinics. Impressively, many clinics reported to see patients within 1-2 days since they focused on the importance of early diagnosis and treatment. This may appear more aspirational for the majority of departments with limitations in resource and funding to deliver such a service. Nevertheless, these examples illustrate the importance of prioritising early RA pathways of care within rheumatology services to optimise efficient diagnosis and management. However, we also recognise that not all recommendations are feasible in every setting, since different clinical structures and workforce challenges may limit the implementation of for example multidisciplinary care approaches. However, the recommendation may hopefully serve as a benchmark to support efforts to obtain more resources to enhance quality of care.

The strength and impact of this paper would have been improved if data had been available on longitudinal clinical outcomes to demonstrate the benefit of the good practice recommendations shown in table 5. Long-term clinical data are available for some of the recommendations and are included in the reference list.

It is envisaged that rheumatology departments could use this study as an initial platform to draw upon models appropriate to local services and pathways for adaptation and implementation. Interested centres are welcome to contact the centres who took part in this study for further knowledge transfer.

The panel of experts recognise that data capture should also be done in the community. Community-based physicians could propose a list of items which, if accepted by rheumatologists, would lead to harmonisation of standards of care across all care settings along the patient journey.

The next steps for the project group are to do additional work on dissemination of our findings. A comprehensive study report has been published on the website of the project accompanied by an appendix with single-centre reports (see Previous publications at the end). More importantly, we also plan to support the implementation of the examples of models of good clinical care into other settings.

In conclusion, we identified 18 models of good clinical practice which are linked to three different disease stages. Further work is needed to explore the ability to implement each of the interventions (eg, the development of tools and manuals detailing their implementation) and the results achieved.

\section{Author affiliations}

${ }^{1}$ Dept. of Rheumatology, Diakonhjemmet Hospital, Oslo, Norway

${ }^{2}$ Hospital Universitario La Paz, Madrid, Spain

${ }^{3}$ Neil Betteridge Associates, London, UK

${ }^{4}$ Centre for Musculoskeletal Research, School of Biological Sciences, University of

Manchester, Manchester, UK

${ }^{5}$ Leeds Institute of Rheumatic \& Musculoskeletal Medicine, Chapel Allerton Hospital, Leeds, UK

${ }^{6}$ Cliniques Universitaires Saint Luc, UCL, Brussels, Belgium

${ }^{7}$ Rheumatology, Gaetano Pini Institute, Milan, Italy

${ }^{8}$ Global Strategy Group, KPMG LLP, London, UK

${ }^{9}$ Department of Internal Medicine Specialties, University Hospitals of Geneva, Geneva, Switzerland

${ }^{10}$ Utrecht University, Utrecht, Netherlands

${ }^{11}$ University of Cologne, Koln, Germany

${ }^{12}$ Radboud University Medical Center Nijmegen, Nijmegen, Netherlands

${ }^{13}$ Sint Maartenskliniek, Nijmegen, Netherlands

${ }^{14}$ Salisbury NHS Foundation Trust, Salisbury, UK

${ }^{15}$ Rheumatology, Karolinska Institutet, Stockholm, Sweden

${ }^{16}$ Copenhagen Center for Arthritis Research, Center for Rheumatology and Spine Diseases, Rigshospitalet, Kobenhavn, Denmark

${ }^{17}$ Rheumatologic Clinic, Institute of Rheumatology, Prague, Czech Republic

${ }^{18}$ Hospital De Santa Maria, Lisboa, Portugal

${ }^{19}$ Respiratory Medicine Unit, Department of Medicine Solna and Center for Molecular Medicine, Karolinska Institutet, Stockholm, Sweden

${ }^{20}$ Department of Respiratory Medicine and Allergy, Karolinska University Hospital

Solna, Karolinska Institutet, Stockholm, Sweden

${ }^{21}$ Hôpital Cochin, Rheumatology, Université Paris Descartes, Paris, France

Acknowledgements The authors thank Sanofi Genzyme who funded this study. The authors are also grateful to Olivia Bryan, Emma Hanson, Jessica 0'Neil, Zoe Philips and Thishi Surendranathan from the KPMG team for their input and contribution to the work.

Contributors All authors contributed to the data collection, to the interpretation and analyses of the results and to the writing of the manuscript. All authors have read and approved the final version of the manuscript submitted on 29 May 2020.

Funding The authors have not declared a specific grant for this research from any funding agency in the public, commercial or not-for-profit sectors.

Competing interests TKK has received fees for speaking and/or consulting from AbbVie, Biogen, Celltrion, Egis, Eli Lilly, Hikma, MSD, Mylan, Novartis, Oktal, Orion Pharma, Pfizer, Roche, Sandoz, Sanofi and UCB and received research funding to Diakonhjemmet Hospital from AbbVie, BMS, MSD, Pfizer, Roche and UCB. AB has received Grant/research support, fees for consultancies or as a speaker for Abbvie, Pfizer, Novartis, BMS, Nordic, Sanofi-Genzyme, Sandoz, Lilly, UCB and Roche. NB has received fees for speaking and/or consulting from Amgen, Eli Lilly, Grunenthal, GSK, Heart Vlavle Voice, Janssen, Roche, Sanofi Genzyme and Sanofi Regeron. MHB has received fees for speaking and/or consulting from AbbVie, AstraZeneca, BristolMyers-Squibb, Chugai, Eli Lilly, Merck-Serono, Pfizer, Roche, Sandoz and Sanofi, and research funding to University of Leeds from Pfizer, Roche and UCB. PD has received fees for speaking and/or consulting from Bristol-Myers-Squibb, Celltrion, Lilly and Sanofi Genzyme. EGF has received fees for speaking and/or consulting from AbbVie, BMS, Eli Lilly, Gilead, MSD, Novartis, Pfizer, Roche, Sanofi-Genzyme and UCB. CG has received fees for consulting from Roche, Sanofi Genzyme, Regeneron, Pfizer, Lilly and Ab2 Bio Ltd. RG has received fees for speaking from Sanofi Genzyme. IG-B has received fees for consulting from Amgen, Akcea, Sanofi Genzyme and Regeneron. FvdH has received fees for consulting from AbbVie, Biogen, Celltron, Roche, Sanofi Genzyme, Pfizer and Munidpharma. AK has received fees for speaking and/or consulting from UCB, Bristol-Myers-Squibb, MSD, Amgen, Abbvie, Pfizer, Novartis and Sanofi. LK has received research grants to Karolinska Institutet from Janssen, Pfizer, BMS, GSK and UCB. Mø has received fees for speaking and/or consulting from Abbvie, Bristol-Myers-Squibb, Boehringer-Ingelheim, Celgene, EliLilly, Hospira, Janssen, Merk, Novartis, Novo, Orion, Pfizer, Regeneron, Roche, Sanofi and UCB. KP has received fees for speaking and/or consulting for AbbVie, 
Amgen, Biogen, Bristol-Myers-Squibb, Egis, MSD and UCB. JP-P has received fees for speaking and/or consulting from AbbVie, MSD, Pfizer, Roche and Tecnimede. AGS has received fees for speaking and/or consulting from AbbVie, Novartis, Sanofi and Bayer and have an unrestricted research collaboration with Eli Lilly which includes transfer of funds to Diakonhjemmet Hospital from Eli Lilly. MS has received research grants from Boehringer Ingelheim and Roche, speakers fee/consultancy from AstraZeneca, Boehringer Ingelheim, GlaxoSmithKline, Novartis, Mundipharma, Sandoz and Roche. MD has received fees for speaking and/or consulting from AbbVie, Biogen, Eli Lilly, BMS, MSD, Novartis, Pfizer, Roche, Sandoz, Sanofi and UCB and his department has received research grants from AbbVie, BMS, MSD, Pfizer, Roche, Lilly, Janssen, Novartis and UCB.

Patient consent for publication Not required.

Provenance and peer review Not commissioned; externally peer reviewed.

Data sharing statement Data are available in a public, open-access repository. All data relevant to the study are included in the article or uploaded as online supplementary information.

Previous publications The main results were previously published as abstracts in ARD related to presentations at EULAR 2019: Kvien TK, Pavelka K, Polido-Pereira J, et al. THU0638 Considerations for improving quality of care in rheumatoid arthritis and associated comorbidities. Ann Rheum Dis. 2019;78 (suppl 2):A613; Betteridge $\mathrm{N}$, Balsa A, Buch M, et al. PARE0018 Enabling patient-centred care in rheumatoid arthritis and associated comorbidities. Ann Rheum Dis. 2019;78 (suppl 2):A2185; Kent A, Gabay C, Geenen R, et al. AB1368-HPR enhanced role of nurses and other healthcare professionals (HCPs) in the care of rheumatoid arthritis and associated comorbidities. Ann Rheum Dis. 2019;78 (suppl 2):A2147. Further, the full report of the project has been published online: https://home.kpmg/content/dam/kpmg/uk/ pdf/2020/02/improving-quality-of-care.pdf.

Open access This is an open access article distributed in accordance with the Creative Commons Attribution Non Commercial (CC BY-NC 4.0) license, which permits others to distribute, remix, adapt, build upon this work noncommercially, and license their derivative works on different terms, provided the original work is properly cited, appropriate credit is given, any changes made indicated, and the use is non-commercial. See: http://creativecommons. org/licenses/by-nc/4.0/.

\section{ORCID iDs}

Tore K Kvien http://orcid.org/0000-0002-8441-3093

Maya H Buch http://orcid.org/0000-0002-8962-5642

Patrick Durez http://orcid.org/0000-0002-7156-2356

Ennio Giulio Favalli http://orcid.org/0000-0003-1471-6467

Guillaume Favier http://orcid.org/0000-0002-6995-5804

Lars Klareskog http://orcid.org/0000-0001-9601-6186

\section{REFERENCES}

1 Song L, Yangsheng Y, Yinshi Y, et al. Microbial infection and rheumatoid arthritis. J Clin Cell Immunol 2013;174.

2 Angel J, Akesson K, Amadio PC, et al. The burden of musculoskeletal conditions at the start of the new millennium. World Health Organization 2003;919:1-218

3 Norton S, Carpenter L, Nikiphorou E, et al. Excess mortality in rheumatoid arthritis: gains in life expectancy over 25 years. Rheumatology Abstract O34. 2014;53:i43-i44.

4 Dougados M, Soubrier M, Antunez A, et al. Prevalence of comorbidities in rheumatoid arthritis and evaluation of their monitoring: results of an international, cross-sectional study (COMORA). Ann Rheum Dis 2014;73:62-8.

5 Radner $\mathrm{H}$, Yoshida K, Smolen J, et al. Multimorbidity and rheumatic conditions - enhancing the concept of comorbidity. Nat Rev Rheumatol 2014;10:252-6.

6 Holmqvist M, Ljung L, Askling J. Acute coronary syndrome in new-onset rheumatoid arthritis: a population-based nationwide cohort study of time trends in risks and excess risks. Ann Rheum Dis 2017;76:1642-7.

7 Bongartz T, Nannini C, Medina-Velasquez Y, et al. Incidence and mortality of interstitial lung disease in rheumatoid arthritis: a population-based study. Arthritis Rheum 2010;62:1583-91.

8 Solomon DH, Love TJ, Canning C, et al. Risk of diabetes among patients with rheumatoid arthritis, psoriatic arthritis and psoriasis. Ann Rheum Dis 2010;69:2114-7.

9 Sheehy C, Murphy E, Barry M. Depression in rheumatoid arthritis: underscoring the problem. Rheumatology 2006;45:1325-7.
10 Matcham F, Rayner L, Steer S, et al. The prevalence of depression in rheumatoid arthritis: a systematic review and meta-analysis. Rheumatology (Oxford) 2013;52:2136-48.

11 Cross M, Smith E, Hoy D, et al. The global burden of rheumatoid arthritis: estimates from the global burden of disease 2010 study. Ann Rheum Dis 2014;73:1316-22.

12 Baillet A, Gossec L, Carmona L, et al. Points to consider for reporting, screening for and preventing selected comorbidities in chronic inflammatory rheumatic diseases in daily practice: a EULAR initiative. Ann Rheum Dis 2016;75:965-73.

13 Winthrop K, Weinblatt M, Crow M, et al. Unmet need in rheumatology: reports from the targeted therapies meeting 2018. Ann Rheum Dis 2019;78:872-8

14 Bosworth A, Hancock T, Hewitt J, et al. Breaking down barriers: rheumatoid arthritis and public awareness. National Rheumatoid Arthritis Society (NRAS), 2013: 1-39.

15 Stack R, Nightingale P, Jinks C, et al. Delays between the onset of symptoms and first rheumatology consultation in patients with rheumatoid arthritis in the UK: an observational study. BMJ Open 2019:9:e024361.

16 Aletaha D, Neogi T, Silman AJ, et al. Rheumatoid arthritis classification criteria: an American College of Rheumatology/European League Against Rheumatism collaborative initiative. Ann Rheum Dis 2010;69:1580-8.

17 National Rheumatoid Arthritis Society (NRAS). Keep taking the pills: the critical importance of adherence in the management of rheumatoid arthritis. 2018.

18 Hider SL, Blagojevic-Bucknall M, Whittle R, et al. What does a primary care annual review for RA include? A national GP survey. Clin Rheumatol 2016;35:2137-8.

19 National Rheumatoid Arthritis Society (NRAS). Rheumatology in Wales, the state of play, 2016.

20 UK Parliament. Early identification and diagnosis of rheumatoid arthritis. 2010.

21 Garneau KL, Iversen MD, Tsao H, et al. Primary care physicians' perspectives towards managing rheumatoid arthritis: room for improvement. Arthritis Res Ther 2011;13:R189.

22 Miltenburger C, Karampampa K, Richard BT, et al. A survey of barriers to treatment access in rheumatoid arthritis. /3 Innovus 2009;5:1-29.

23 Marengo M, Suarez-Almazor M. Improving treatment adherence in patients with rheumatoid arthritis: what are the options. Int J Clin Rheumatol 2015;10:345-56.

24 National Rheumatoid Arthritis Society (NRAS). The impact of rheumatoid arthritis comorbidities. 2012: 1-29.

25 Peters MJL, Symmons DPM, McCarey D, et al. EULAR evidence-based recommendations for cardiovascular risk management in patients with rheumatoid arthritis and other forms of inflammatory arthritis. Ann Rheum Dis 2010;69:325-31.

26 Bartels CM, Saucier JM, Thorpe CT, et al. Monitoring diabetes in patients with and without rheumatoid arthritis: a medicare study. Arthritis Res Ther 2012;14:1-9.

27 Selmi C, Santis M, Gershwin M. Liver involvement in subjects with rheumatic disease. Arthritis Res Ther 2011:13:226.

28 Corrales A, González-Juanatey C, Peiró ME, et al. Carotid ultrasound is useful for the cardiovascular risk stratification of patients with rheumatoid arthritis: results of a population-based study. Ann Rheum Dis 2014;73:722-7.

29 Nakajima A, Inoue E, Shimizu Y, et al. Presence of comorbidity affects both treatment strategies and outcomes in disease activity, physical function, and quality of life in patients with rheumatoid arthritis. Clin Rheumatol 2015;34:441-9.

30 Agca R, Heslinga S, Rollefstad S, et al. EULAR recommendations for cardiovascular disease risk management in patients with rheumatoid arthritis and other forms of inflammatory joint disorders: 2015/2016 update. Ann Rheum Dis 2017;76:17-28.

31 Mach F, Baigent C, Catapano A, et al. European Society of Cardiology/ European Atherosclerosis Society Guidelines for the management of dyslipidaemias: lipid modification to reduce cardiovascular risk. Eur Heart J 2019;00:1-78.

32 Andreu Sanchez JL, Balsa A, Gualda E, et al. Update of the clinical practice guideline for the management of rheumatoid arthritis in Spain. Spanish Soc Rheumatol 2011.

33 André-Vert J, Guillez P, Scémama O. Clinical practice guidelines: rheumatoid arthritis - medical, social and organisational aspects of treatment (excluding surgery and drugs). Haute Autorite De Sante, 2017.

34 Raghu G, Remy-Jardin M, Myerset J, et al. Diagnosis of idiopathic pulmonary fibrosis. An official ATS/ERS/JRS/ALAT clinical practice guideline. Am J Respir Crit Care Med 2018;198:44-68.

35 Skold M. Idiopatisk Lungfibros, Vårdprogram. Swedish Respiratory Society, 2019 
36 Pilling S, Anderson I, Goldberg D, et al. Depression in adults with a chronic physical health problem: recognition and management. NICE 2009.

37 Smolen JS, Landewé R, Bijlsma J, et al. EULAR recommendations for the management of rheumatoid arthritis with synthetic and biological disease-modifying antirheumatic drugs: 2016 update. Ann Rheum Dis 2017;76:960-77.

38 Villeneuve E, Nam JL, Bell MJ, et al. A systematic literature review of strategies promoting early referral and reducing delays in the diagnosis and management of inflammatory arthritis. Ann Rheum Dis 2013;72:13-22.

39 Dixon WG, Hyrich KL, Watson KD, et al. Influence of anti-TNF therapy on mortality in patients with rheumatoid arthritis-associated interstitial lung disease: results from the British Society for Rheumatology Biologics Register. Ann Rheum Dis 2010;69:1086-91.

40 Radner H, Chatzidionysiou K, Nikiphorou E, et al. 2017 EULAR recommendations for a core data set to support observational research and clinical care in rheumatoid arthritis. Ann Rheum Dis 2018;77:476-9.

41 Eriksson J, Askling J, Arkema E. The Swedish rheumatology quality register: optimisation of rheumatic disease assessments using register-enriched data. Clin Exp Rheumatol 2014;32:S147-9.

42 Doyle C, Lennox L, Bell D. A systematic review of evidence on the links between patient experience and clinical safety and effectiveness. BMJ Open 2013;3:1-18.

43 Vare $\mathrm{P}$, Nikiphorou E, Hannonen $\mathrm{P}$, et al. Delivering a one-stop, integrated, and patient-centered service for patients with rheumatic diseases. SAGE Open Med 2016;4:2050312116654404.

44 Arts EE, Popa C, Den Broeder AA, et al. Performance of four current risk algorithms in predicting cardiovascular events in patients with early rheumatoid arthritis. Ann Rheum Dis 2015;74:668-74.

45 Crowson C, Matteson EL, Roger VL, et al. Usefulness of risk scores to estimate the risk of cardiovascular disease in patients with rheumatoid arthritis. Am J Cardiol 2012:110:420-4.

46 Ørstavik RE, Haugeberg G, Mowinckel P, et al. Vertebral deformities in rheumatoid arthritis: a comparison with population-based controls. Arch Intern Med 2004;23:420-5.

47 Semb AG, Ikdahl E, Hisdal J, et al. Exploring cardiovascular disease risk evaluation in patients with inflammatory joint diseases. Int J Cardiol 2016;223:331-6.

48 Rollefstad S, Kvien TK, Holme I, et al. Treatment to lipid targets in patients with inflammatory joint diseases in a preventive cardio-rheuma clinic. Ann Rheum Dis 2013;72:1968-74.
49 Rollefstad S, Ikdahl E, Hisdal J, et al. Systemic inflammation in patients with inflammatory joint diseases does not influence statin dose needed to obtain LDL cholesterol goal in cardiovascular prevention. Ann Rheum Dis 2015;74:1544-50.

50 Otsuka Y, Kiyohara C, Kashiwado Y, et al. Effects of tumor necrosis factor inhibitors and tocilizumab on the glycosylated hemoglobin levels in patients with rheumatoid arthritis; an observational study. PLoS One 2018;13:e0196368.

51 Haugeberg G, Uhlig T, Falch JA, et al. Bone mineral density and frequency of osteoporosis in female patients with rheumatoid arthritis: results from 394 patients in the Oslo County Rheumatoid Arthritis register. Arthritis Rheum 2000;43:522-30.

52 Haugeberg G, Uhlig T, Falch JA, et al. Reduced bone mineral density in male rheumatoid arthritis patients: frequencies and associations with demographic and disease variables in ninety-four patients in the Oslo County Rheumatoid Arthritis Register. Arthritis Rheum 2000;43:2776-84.

53 Ørstavik RE, Haugeberg G, Uhlig T, et al. Self-reported non-vertebral fractures in rheumatoid arthritis and population based controls: incidence and relationship with bone mineral density and clinical variables. Ann Rheum Dis 2004;63:177-82.

54 Furer V, Rondaan C, Heijstek M, et al. 2019 update of EULAR recommendations for vaccination in adult patients with autoimmune inflammatory rheumatic diseases. Ann Rheum Dis 2020;79:39-52

55 Winthrop L. Update on tuberculosis and other opportunistic infections associated with drugs blocking tumour necrosis factor $\alpha$. Ann Rheum Dis 2005;64:29-30.

56 Rodríguez-Lozano B, González-Febles J, Garnier-Rodríguez J, et al. Association between severity of periodontitis and clinical activity in rheumatoid arthritis patients: a case: control study. Arthritis Res Ther 2019;21:27

57 Nayak P, Luo R, Elting L, et al. Impact of rheumatoid arthritis on the mortality of elderly patients who develop cancer: a population-based study. Arthritis Care Res 2017;69:75-83.

58 Van den Hoek J, Boshuizen HC, Roorda LD, et al. Association of somatic comorbidities and comorbid depression with mortality in patients with rheumatoid arthritis: a 14-year prospective cohort study. Arthritis Care Res 2016;68: 1055-60. 